\title{
Clinical effect of intramuscular calcitonin compared with oral celecoxib in the treatment of knee bone marrow lesions: a retrospective study
}

Jiaming Zhou ${ }^{1,2+}$, Wuyi Xiong ${ }^{1,2+}$, Pengguo Gou ${ }^{1,3+}$, Zhao Chen ${ }^{1}$, Xing Guo ${ }^{1}$, Xiaoyang Huo ${ }^{1}$ and Yuan Xue ${ }^{1,2^{*}}$

\begin{abstract}
Background: Bone marrow lesions (BMLs) are a common finding in patients with osteoarthritis (OA), which are predictors of progression and pain related to cartilage damage in OA. The objective of the present research was to compare the short-term clinical effect of intramuscular calcitonin and oral celecoxib in treating knee BMLs.

Patients and methods: Between January 2016 and December 2018, the medical records of patients with knee BMLs treated by intramuscular calcitonin or oral celecoxib were reviewed. Visual analog scale (VAS) and the Western Ontario and McMaster University Osteoarthritis Index (WOMAC) were used to assess knee pain and function, respectively. BMLs were assessed by MRI scans and were scored by the modified Whole-Organ MRI Score (WORMS). The safety of these two medications was also evaluated.

Results: A total of 123 eligible patients who received calcitonin treatment $(n=66)$ or celecoxib treatment $(n=57)$ were included. All patients were followed up clinically and radiographically for 3 months. The VAS and WOMAC scores were lower statistically in calcitonin group than celecoxib group at 4-week and 3-month follow-up. For BMLs, the WORMS scores in the calcitonin group were significantly lower than the celecoxib group. Besides, statistically higher MRI improvement rates were found in the calcitonin group compared with the celecoxib group at 4-week follow-up (21.21\% vs. 7.01\%; $P=0.039)$ and 3 -month follow-up (37.88\% vs. $15.79 \% ; ~ P=0.006)$.
\end{abstract}

Conclusion: Intramuscular calcitonin $50 \mathrm{IU}$ once daily demonstrated a better short-term effect for knee BML patients compared with oral celecoxib 200 mg twice per day.

Keywords: Calcitonin, Celecoxib, Bone marrow lesions, Osteoarthritis

\footnotetext{
* Correspondence: xueyuanzyy@163.com

${ }^{\dagger}$ Jiaming Zhou, Wuyi Xiong and Pengguo Gou contributed equally to this work.

'Department of Orthopaedic Surgery, Tianjin Medical University General Hospital, Tianjin 300052, China

${ }^{2}$ Tianjin Key Laboratory of Spine and Spinal Cord, Tianjin Medical University General Hospital, Tianjin 300052, China

Full list of author information is available at the end of the article
}

(c) The Author(s). 2020 Open Access This article is licensed under a Creative Commons Attribution 4.0 International License, which permits use, sharing, adaptation, distribution and reproduction in any medium or format, as long as you give appropriate credit to the original author(s) and the source, provide a link to the Creative Commons licence, and indicate if changes were made. The images or other third party material in this article are included in the article's Creative Commons licence, unless indicated otherwise in a credit line to the material. If material is not included in the article's Creative Commons licence and your intended use is not permitted by statutory regulation or exceeds the permitted use, you will need to obtain permission directly from the copyright holder. To view a copy of this licence, visit http://creativecommons.org/licenses/by/4.0/ The Creative Commons Public Domain Dedication waiver (http://creativecommons.org/publicdomain/zero/1.0/) applies to the data made available in this article, unless otherwise stated in a credit line to the data. 


\section{Background}

Knee osteoarthritis (OA), the most common joint disease around the world, often leads to pain, stiffness, or even loss of function [1-5]. When patients suffer from knee pain, bone marrow lesions (BMLs) are a common finding in magnetic resonance imaging (MRI) and are characterized by a hyperintensity in the marrow in fatsuppressed T2-weighted images, which are a reversible but highly painful manifestation in patients with knee pain [6]. Felson et al. reported that patients with knee OA concomitant BMLs had a higher incidence of knee pain than those with a similar degree of radiographic knee OA but without BMLs [7]. It is well known that various diagnoses, especially degenerative arthritis, could contribute to BMLs $[6,8]$. The exact pathogenetic processes and role of painful BMLs in OA knees are not currently known. For patients with this issue, the best treatment is still unclear.

Patients with knee OA often suffer joint pain and are usually treated using nonsteroidal anti-inflammatory drugs (NSAIDs), opioid analgesics, and intra-articular injection such as hyaluronic acid, corticosteroids, and platelet-rich plasma $[9,10]$. Oral NSAIDs are the most frequently used pharmaceuticals for pain control and are usually recommended in the OA Clinical Practice Guidelines for the treatment of widespread OA to relieve pain [11-13]. However, because these drugs are related to gastrointestinal and cardiorenal toxicity and are ineffective in some patients, it is necessary to develop specific and efficacious drugs for patients with knee OA suffering from pain.

Calcitonin is an anti-osteoclastic drug and can effectively inhibit the bone resorption of osteoclasts and has been proved to be effective in osteoporosis and other diseases which involved accelerated bone turnover [14, 15]. It could significantly antagonize subcartilage bone changes, alleviate cartilage degradation, and prevent the net loss of collagen, hyaluronic acid, and proteoglycan in OA animal models [16-18]. In patients with OA, calcitonin was found to improve dysfunction, reduce cartilage degeneration, and reduce the level of biomarkers for bone resorption and cartilage degeneration [19-21]. Meanwhile, in a microarray analysis, increased bone turnover was found in BMLs [22]. Hence, calcitonin may have potential as a method for treating knee BMLs. To our knowledge, the effect of calcitonin in knee BMLs has not been investigated in previous study. Celecoxib was chosen as the comparator because celecoxib is superior to other NSAIDs owing to a lower incidence of gastrointestinal side effects [23]. In addition, celecoxib is effective in the treatment and wide application of knee OA which can improve pain, movement, and quality of life [24]. OA is a main cause of disability and impairs quality of life in older adults, particularly when the knee is affected [25]. Many patients imminently hope to relieve symptoms as soon as possible in order to reintegrate into society. We hypothesized that intramuscular calcitonin had better short-term clinical effect compared with oral celecoxib for knee BMLs. Hence, the current research aimed to explore the clinical effect of intramuscular calcitonin compared with oral celecoxib in treating knee BML patients.

\section{Patients and methods \\ Patients}

We reviewed 152 consecutive patients in our hospital who were diagnosed with early- to mid-stage knee OA and BMLs (Fig. 1a) between January 2016 and December 2018 according to the diagnostic criteria of the American College of Rheumatology [26, 27].

The severity of OA was evaluated by KellgrenLawrence (K-L) grading score through X-ray. The BMLs were defined as an alteration in bone marrow signal intensity, with ill-defined hyperintensity in fat-suppressed T2-weighted MRI images [28-30]. Using the modified Whole-Organ MRI Score (WORMS), BMLs were classified as $0-3$ using the largest percentage of bone area in the entire subregion (three lesion subregions: anterior, central, and posterior, and there was an additional subregion of the tibia representing the subspine of the tibia) as follows: 0 , none; $1,1-25 \%$ of the subregion; $2,26-$ $50 \%$ of the subregion; $3,51-100 \%$ of the subregion [31]. The total scores of the knee BMLs were obtained by adding the BML scores of all sites, and the total score range of the knee BMLs was $0-45$. BML scores $\geq 1$ in any subregion was defined as the presence of BMLs in the entire knee.

Patients who had the following characteristics were excluded: (1) bilateral knee OA $(n=11)$ and (2) lack of adequate follow-up data $(n=18)$. Finally, 123 patients were included in this study. All the patients had earlyto mid-stage knee OA and BMLs, with severity grade 13 according to Kellgren-Lawrence (K-L) grading score.

\section{Treatment}

One hundred and twenty-three patients were retrospectively studied. Both medications were prescribed by two senior physicians (YX and PG). YX prescribed intramuscular calcitonin for patients if they meet the indications as follows: knee OA with severity grade $1-3$ according to $\mathrm{K}-\mathrm{L}$ grading score on X-ray and BMLs on MRI. PG routinely prescribed celecoxib for patients with grade 13 knee OA, no matter whether BMLs existed on MRI. A total of 66 patients received an intramuscular injection of $50 \mathrm{IU}$ of calcitonin (Miacalcic ${ }^{\circ}$, Novartis Pharma Schweiz AG, Rotkreuz, Switzerland) once daily, and 57 patients received $200 \mathrm{mg}$ of celecoxib (Celebrex ${ }^{\circ}$, Pfizer Inc., New York, USA) orally twice daily for 4 weeks. In 

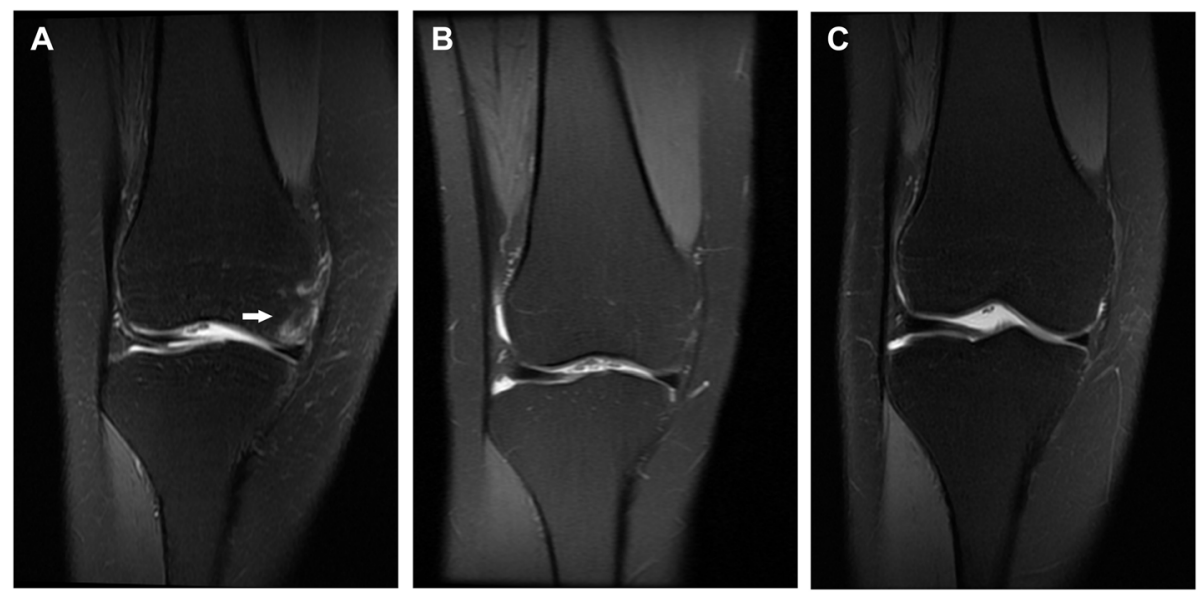

Fig. 1 A patient with BMLs (arrow) on MRI: hyperintensity on fat-suppressed T2-weighted image (a). After calcitonin treatment, no abnormal signal intensity was found at 4-week follow-up (b) and 3-month follow-up (c). BMLs bone marrow lesions, MRI magnetic resonance imaging

addition, all patients received the same basic treatment including health education, physical therapy, and weight-bearing restrictions. Unloader brace, calcium, or vitamin D supplements were not given to any patients. Baseline data for all patients, including age, gender, smoking, body mass index (BMI), and knee OA image data, were collected from clinical records. At each follow-up, patients' data were collected.

\section{Post-intervention assessment}

The post-intervention assessment included knee pain and function using the VAS and the Western Ontario and McMaster University Osteoarthritis Index (WOMAC) scores and adverse events, which were recorded at baseline and at 1,2 , and 4 weeks and 3 months after treatment. VAS scores ranged from 0 to 10 for the assessment of knee pain perception [32]. WOMAC is a validated survey including three domains, namely joint pain (0-20), stiffness $(0-8)$, and the limitation of physical function (0-68) [33].

\section{Evaluation of imaging data}

Four weeks and three months after treatment, patients were asked to undergo a knee MRI. All studies were performed in one center on the same equipment (Discovery MR750, General Electric, Milwaukee, Wisconsin, USA). Using WORMS, the BMLs were scored. The changes in the BML scores were calculated by subtracting the follow-up total knee BML scores from the total knee BML scores at baseline. A decrease in BML scores of more than 1 was considered to be an effective improvement [34].

Two researchers (JZ and WX) collected and reviewed all of the imaging data. To guarantee data reliability, they held regular meetings and discussions. The intraclass correlation coefficients of intraobserver and interobserver reproducibility for WORMS were 0.94 and
0.90 , respectively. MRI was performed at baseline and 4week and 3-month follow-up. In addition, changes and scores for the BMLs were assessed. One patient with BMLs treated using calcitonin is illustrated in Fig. 1. The BML improvement rate was also calculated.

\section{Power analysis}

Based on previous studies and our pilot experiment, we assumed normal distribution and a VAS standard deviation (SD) of 0.8 . With a two-sided $\alpha=0.05$, a sample size of 42 patients in each group gave a power of 0.8 to detect a mean difference of 0.5 in VAS.

\section{Statistical analysis}

All results are expressed as mean values \pm standard deviation or frequencies (with proportions). Differences between groups of continuous variables and categorical variables were analyzed by independent sample $t$ test and chi-square test, respectively. Intragroup differences were analyzed using a paired $t$ test. SPSS 21.0 (IBM Corp, Armonk, NY, USA) was performed to analyze all of these data, and a $P$ value less than 0.05 was accepted to be statistically significant.

\section{Results}

\section{Baseline characteristics}

A total of 123 patients (69 men and 54 women) were enrolled with a mean \pm SD age of $60.47 \pm 9.54$ years, and a mean BMI of $25.84 \pm 4.83 \mathrm{~kg} / \mathrm{m}^{2}$. According to the K-L criteria, 21 patients were grade 1, 44 patients were grade 2 , and 58 patients were grade 3 . No statistical differences were found between the two groups in age, gender, smoking, BMI, VAS, WOMAC, and BML scores $(P>0.05)$ (Table 1$)$. 
Table 1 Baseline characteristics of patients

\begin{tabular}{|c|c|c|c|}
\hline Characteristics & Calcitonin $(n=66)$ & Celecoxib $(n=57)$ & $P$ value \\
\hline Age, mean (years) $\pm S D$ & $59.49 \pm 9.32$ & $61.54 \pm 8.48$ & 0.620 \\
\hline Sex, n (male) (\%) & $38(57.58)$ & $31(54.39)$ & 0.722 \\
\hline Smokers, n (\%) & $24(36.36)$ & $21(36.84)$ & 0.956 \\
\hline BMI, mean $\left(\mathrm{kg} / \mathrm{m}^{2}\right) \pm \mathrm{SD}$ & $26.38 \pm 4.12$ & $25.31 \pm 5.50$ & 0.481 \\
\hline Pain VAS scores (0-10) & $6.48 \pm 1.08$ & $6.52 \pm 0.87$ & 0.876 \\
\hline \multicolumn{4}{|l|}{ WOMAC scores } \\
\hline Total scores (0-96) & $54.09 \pm 10.24$ & $54.60 \pm 10.88$ & 0.878 \\
\hline Pain scores $(0-20)$ & $12.08 \pm 4.09$ & $12.15 \pm 2.62$ & 0.943 \\
\hline Stiffness scores (0-8) & $4.95 \pm 0.97$ & $4.90 \pm 0.70$ & 0.857 \\
\hline Physical function scores (0-68) & $37.07 \pm 9.54$ & $37.54 \pm 11.31$ & 0.883 \\
\hline \multicolumn{4}{|l|}{ Kellgren-Lawrence criteria, $n$ (\%) } \\
\hline Grade 1 & $11(16.67 \%)$ & $10(17.54 \%)$ & \multirow[t]{3}{*}{0.986} \\
\hline Grade 2 & $24(36.37 \%)$ & $20(35.09 \%)$ & \\
\hline Grade 3 & $31(49.96 \%)$ & $27(47.37 \%)$ & \\
\hline BMLs scores & $4.90 \pm 1.35$ & $4.95 \pm 1.08$ & 0.856 \\
\hline
\end{tabular}

BMI body mass index, VAS visual analog scale, WOMAC Western Ontario and McMaster Universities Osteoarthritis Index, BMLs bone marrow lesions

\section{Clinical outcome}

Symptoms of the disease decreased over time in both therapeutic groups, and differences between the VAS scores for pain and the WOMAC scores in both groups are shown in Table 2. Both calcitonin and celecoxib had an onset of response and provide pain relief and improvement of stiffness and physical function. The VAS and WOMAC scores were significantly improved compared with the baseline data in the two groups. Moreover, the VAS and WOMAC scores in the calcitonin group decreased more significantly compared with the celecoxib group.

\section{BML imaging data}

The patients between the two groups showed a similar BML scores at baseline $(P>0.05)$ (Table 1$)$. Based on MRI results, significantly lower BML scores were found in the calcitonin group compared with the celecoxib group at 4-week follow-up $(4.28 \pm 1.41$ vs. $4.83 \pm 1.01)$ and 3 -month follow-up $(3.63 \pm 1.55$ vs. $4.35 \pm 1.22)$ (Table 3). In addition, BML changes scores in the calcitonin group showed statistical improvements compared with the celecoxib group. MRI examination results of the two groups also showed the patients in the calcitonin group had higher MRI improvement rate at 4-week follow-up (21.21\% vs. 7.01\%; $P=0.039)$ and 3-month follow-up (37.88\% vs. $15.79 \% ; P=0.006)$ (Table 4 ).

\section{Adverse events}

Seven patients $(10.61 \%)$ in the calcitonin group and six patients $(10.53 \%)$ in the celecoxib group reported at least one adverse event, with no significant differences $(P=$
0.966). Diarrhea $(1 ; 1.52 \%)$, nausea $(1 ; 1.52 \%)$, headache (2; $3.03 \%)$, hot flushes $(3 ; 4.55 \%)$, and hypocalcemia (2; $3.03 \%)$ were reported in the calcitonin group. Gastroesophageal reflux disease (2;3.51\%), hypodynamia (3; $5.26 \%)$, headache $(2 ; 3.51 \%)$, and dizziness $(1 ; 1.75 \%)$ occurred in the celecoxib group.

\section{Discussion}

$\mathrm{OA}$ is the most common progressive joint disease and responsible for pain, disability, debilitation, and socioeconomic cost worldwide [1-5]. We observed that for knee BMLs, $50 \mathrm{IU}$ of calcitonin intramuscularly per day had a more beneficial effect than oral administration of $200 \mathrm{mg}$ twice per day of celecoxib. The lower VAS and WOMAC scores were found in the calcitonin group which had lower BML scores and higher MRI improvement rates based on MRI examination results at 4-week and 3-month follow-up compared with the celecoxib group. The current study showed the same result that a decrease in BMLs reduced the pain which was in line with several studies $[7,8,30,31]$, and treatment of osteoarthritis might benefit from a lesion-specific therapeutic approach by reducing the area of BMLs [35].

BMLs, representing focal bone remodeling because of excessive loading, are predictors of progression and pain related to cartilage damage in OA $[34,36]$. A decreased risk of cartilage loss was associated with the absence of BMLs, and progressive and new BMLs presented a higher risk of cartilage loss in the same subregion [37]. BMLs are also closely related to dysplasia of the affected side which increases the risk of structural progression in knee OA [8, 28]. In addition, Felson and coworkers 
Table 2 Comparison of clinical outcomes between two groups

\begin{tabular}{|c|c|c|c|}
\hline Characteristics & Calcitonin $(n=66)$ & Celecoxib $(n=57)$ & $P$ value \\
\hline \multicolumn{4}{|c|}{ Pain VAS scores (0-10) } \\
\hline Baseline & $6.48 \pm 1.08$ & $6.52 \pm 0.87$ & 0.876 \\
\hline 1 week & $4.95 \pm 1.28^{*}$ & $5.76 \pm 0.89^{*}$ & 0.022 \\
\hline 2 weeks & $3.71 \pm 0.96^{*}$ & $4.62 \pm 0.92^{*}$ & 0.003 \\
\hline 4 weeks & $2.95 \pm 0.80^{*}$ & $3.57 \pm 0.87^{*}$ & 0.021 \\
\hline 3 months & $1.86 \pm 0.65^{*}$ & $2.57 \pm 0.81^{*}$ & 0.008 \\
\hline \multicolumn{4}{|l|}{ WOMAC scores } \\
\hline \multicolumn{4}{|c|}{ Total scores (0-96) } \\
\hline Baseline & $54.09 \pm 10.24$ & $54.60 \pm 10.88$ & 0.878 \\
\hline 1 week & $41.00 \pm 8.84^{*}$ & $49.89 \pm 10.45$ & 0.005 \\
\hline 2 weeks & $35.07 \pm 7.43^{*}$ & $44.24 \pm 10.10^{*}$ & 0.002 \\
\hline 4 weeks & $31.45 \pm 6.67^{*}$ & $39.80 \pm 8.63^{*}$ & 0.001 \\
\hline 3 months & $26.92 \pm 6.81^{*}$ & $36.01 \pm 7.93^{*}$ & $<0.001$ \\
\hline \multicolumn{4}{|c|}{ Pain scores (0-20) } \\
\hline Baseline & $12.08 \pm 4.09$ & $12.15 \pm 2.62$ & 0.943 \\
\hline 1 week & $8.89 \pm 3.25^{*}$ & $10.87 \pm 2.41$ & 0.031 \\
\hline 2 weeks & $7.57 \pm 2.53^{*}$ & $9.82 \pm 2.06^{*}$ & 0.003 \\
\hline 4 weeks & $6.82 \pm 2.19^{*}$ & $8.48 \pm 1.80^{*}$ & 0.011 \\
\hline 3 months & $5.78 \pm 1.55^{*}$ & $7.70 \pm 1.63^{*}$ & $<0.001$ \\
\hline \multicolumn{4}{|c|}{ Stiffness scores (0-8) } \\
\hline Baseline & $4.95 \pm 0.97$ & $4.90 \pm 0.70$ & 0.857 \\
\hline 1 week & $4.10 \pm 0.89^{*}$ & $4.62 \pm 0.67$ & 0.037 \\
\hline 2 weeks & $3.29 \pm 0.90^{*}$ & $3.95 \pm 0.86^{*}$ & 0.019 \\
\hline 4 weeks & $2.67 \pm 0.86^{*}$ & $3.62 \pm 0.67^{*}$ & 0.001 \\
\hline 3 months & $2.00 \pm 0.84^{*}$ & $2.95 \pm 0.92^{*}$ & $<0.001$ \\
\hline \multicolumn{4}{|c|}{ Physical function scores (0-68) } \\
\hline Baseline & $37.07 \pm 9.54$ & $37.54 \pm 11.31$ & 0.883 \\
\hline 1 week & $28.02 \pm 8.11^{*}$ & $34.40 \pm 11.00$ & 0.039 \\
\hline 2 weeks & $24.21 \pm 7.15^{*}$ & $30.48 \pm 9.47^{*}$ & 0.020 \\
\hline 4 weeks & $21.96 \pm 6.44^{*}$ & $27.70 \pm 9.04^{*}$ & 0.023 \\
\hline 3 months & $19.14 \pm 6.84^{*}$ & $25.35 \pm 8.39^{*}$ & 0.012 \\
\hline
\end{tabular}

VAS visual analog scale, WOMAC Western Ontario and McMaster Universities Osteoarthritis Index

${ }^{*} P<0.05$ vs baseline

Table 3 BMLs scores changed between two groups

\begin{tabular}{|c|c|c|c|c|c|c|}
\hline & \multicolumn{3}{|l|}{ Original values } & \multicolumn{3}{|l|}{ Changes } \\
\hline & Calcitonin $(n=66)$ & Celecoxib $(n=57)$ & $P$ value & Calcitonin $(n=66)$ & Celecoxib $(n=57)$ & $P$ value \\
\hline Baseline & $4.90 \pm 1.35$ & $4.95 \pm 1.08$ & 0.856 & & & \\
\hline 4 weeks & $4.28 \pm 1.41^{*}$ & $4.83 \pm 1.01$ & 0.049 & $0.62 \pm 1.15$ & $0.12 \pm 0.46$ & 0.014 \\
\hline 3 months & $3.63 \pm 1.55^{*}$ & $4.35 \pm 1.22^{*}$ & 0.005 & $1.27 \pm 1.50$ & $0.60 \pm 1.17$ & 0.028 \\
\hline
\end{tabular}


Table 4 Percentage of patients with improved BMLs

\begin{tabular}{llll}
\hline & Calcitonin $(n=66)$ & Celecoxib $(n=57)$ & $P$ value \\
\hline 4 weeks & $14(21.21 \%)$ & $4(7.01 \%)$ & 0.039 \\
3 months & $25(37.88 \%)$ & $9(15.79 \%)$ & 0.006 \\
\hline
\end{tabular}

$B M L s$ bone marrow lesions

founded that BMLs markedly increase the risk for structural deterioration and an increase in BMLs was related to the development of knee pain [28, 34]. Celecoxib, one of the NSAIDs which selectively inhibit COX-2, has been extensively used in the treatment of chronic pain such as osteoarthritis and rheumatoid arthritis [38]. However, celecoxib was found to have a neutral effect similar to placebo on cartilage volume loss in knee OA patients [39], and for patients with knee OA, a randomized controlled trial using MRI shown no difference between celecoxib and placebo in the progression of cartilage volume loss [40].

Calcitonin is a natural polypeptide that acts on specific receptors to effectively inhibit osteoclast function [41]. The significant protective effect of calcitonin in OA cartilage has been shown by previous studies $[17,18,42$, 43]. Furthermore, salmon calcitonin has been shown to resist cartilage degradation and resist bone resorption in the OA knee [7, 44]. Therefore, calcitonin has a dual protective effect in cartilage and subchondral bone and could be used in knee BMLs. In this research, all the enrolled knee OA patients demonstrated BMLs and significant improvement rates of BMLs were found in the calcitonin group compared with the celecoxib group. Besides, calcitonin has already been shown to have a beneficial effect on BMLs such as calcitonin has been used by a few researchers to treat hip BMLs $[45,46]$ and has been confirmed to provide a beneficial effect in lumbar BMLs, also known as type I Modic changes [47]. In addition, cartilage lesions are a common type of joint pathologic change in OA. The characteristics of chondroextracellular matrix imbalance include loss of matrix components and an increase in matrix degradation protease levels, which plays a vital part in the evolution of OA [48, 49]. However, it should be noted that in both groups, the pain and function improvements were gradually relieved. This phenomenon in the celecoxib group was unusual because celecoxib is a systemic rapid onset drug for $\mathrm{OA}$, with the maximum pain-relieving effect at 2-4 weeks (mean 2.3 weeks) $[50,51]$. One possible reason is that the pain of OA is complicated and could originate from BMLs, synovitis, effusions, periarticular lesions, and bursitis [52]. In this study, all patients demonstrated BMLs on MRI, and hence, the major cause of pain may originate from BMLs for these patients. The local high turnover of BMLs has been confirmed [53, 54], which might explain why anti-absorbents such as calcitonin could play an effective role on the extensive symptoms related with the lesions [55]. However, few literatures reported the efficacy of celecoxib in BMLs. We suppose that the effect of celecoxib in BMLs might be relatively insensitive and the time of maximal effect was delayed. Nevertheless, the mechanisms of pain in BMLs and the effect of calcitonin and celecoxib in this condition still need to be studied.

The current study had some limitations. This study is limited by the lack of randomization, which might lead to potential bias. Besides, a placebo group was not included in this research because all eligible patients were diagnosed by two physicians, one of whom treated patients with calcitonin and the other with celecoxib. In addition, although the MRI was performed on the same equipment and high intra- and inter-observer reliability of WORMS were found, the MRI protocol was not standardized. Moreover, the sample size in this study was not large enough. Further randomized placebo-controlled studies are needed to evaluate the clinical effect of calcitonin and celecoxib in BMLs.

\section{Conclusion}

In summary, the results of the present study indicated that compared with celecoxib, intramuscular calcitonin provided a greater short-term clinical efficacy in the treatment of knee BMLs patients.

\section{Abbreviations \\ BMI: Body mass index; BMLs: Bone marrow lesions; MRI: Magnetic resonance imaging; NSAIDs: Nonsteroidal anti-inflammatory drugs; OA: Osteoarthritis; VAS: Visual analog scale; WOMAC: Western Ontario and McMaster Universities Osteoarthritis Index; WORMS: Whole-Organ MRI Score}

\section{Acknowledgements}

Not applicable.

\section{Authors' contributions}

$J Z, W X$, and $P G$ participated in the data collection and drafted the manuscript. ZC and XG participated in the design of the study and performed the statistical analysis. XH performed the statistical analysis. YX conceived of the study, participated in its design and coordination, and helped to draft the manuscript. All authors read and approved the final manuscript.

\section{Funding}

This study was funded by National Natural Science Foundation of China (grant no. 81871124).

\section{Availability of data and materials}

Please contact the author for data requests.

\section{Ethics approval and consent to participate}

The study was approved by the Medical Ethics Committee of Tianjin Medical University General Hospital (China) with ethical no. IRB2019-WZ-070 and was conducted in accordance with the ethical standards of the Declaration of Helsinki and its later amendments. All patients received information about the study and agreed to participate by signing the informed consent form. Informed consent was obtained from all individual participants included in the study.

Consent for publication

Not applicable. 


\section{Competing interests}

The authors declare that they have no competing interests.

\section{Author details}

'Department of Orthopaedic Surgery, Tianjin Medical University General Hospital, Tianjin 300052, China. ${ }^{2}$ Tianjin Key Laboratory of Spine and Spinal Cord, Tianjin Medical University General Hospital, Tianjin 300052, China. ${ }^{3}$ Department of Orthopaedic Surgery, The Fifth People's Hospital of Datong, Datong 037006, China.

\section{Received: 6 February 2020 Accepted: 16 June 2020}

\section{Published online: 23 June 2020}

\section{References}

1. GBD 2015 Disease and Injury Incidence and Prevalence Collaborators. Global, regional, and national incidence, prevalence, and years lived with disability for 310 diseases and injuries, 1990-2015: a systematic analysis for the Global Burden of Disease Study 2015. Lancet. 2016;388:1545-602.

2. Mokdad AH, Ballestros K, Echko M, et al. The state of US Health, 1990-2016: burden of diseases, injuries, and risk factors among US states. JAMA. 2018; 319:1444-72.

3. Glyn-Jones S, Palmer AJ, Agricola R, et al. Osteoarthritis. Lancet. 2015;386: $376-87$.

4. Murray CJ, Vos T, Lozano R, et al. Disability-adjusted life years (DALYS) for 291 diseases and injuries in 21 regions, 1990-2010: a systematic analysis for the Global Burden of Disease Study 2010. Lancet. 2012;380:2197-223.

5. Woolf AD, Pfleger B. Burden of major musculoskeletal conditions. Bull World Health Organ. 2003;81:646-56.

6. Berger $\mathrm{CE}$, Kroner $\mathrm{AH}$, Kristen $\mathrm{KH}$, et al. Transient bone marrow edema syndrome of the knee: clinical and magnetic resonance imaging results at 5 years after core decompression. Arthroscopy. 2006;22:866-71.

7. Felson DT, Chaisson CE, Hill CL, et al. The association of bone marrow lesions with pain in knee osteoarthritis. Ann Intern Med. 2001;134:541-9.

8. Kesemenli CC, Memisoglu K, Muezzinoglu US, Akansel G. Treatment for painful bone marrow edema by open wedge tibial osteotomy. Eur J Orthop Surg Traumatol. 2013;23:825-9.

9. Jones IA, Togashi R, Wilson ML, Heckmann N, Vangsness $C T$. Intra-articular treatment options for knee osteoarthritis. Nat Rev Rheumatol. 2019;15:7790.

10. Abramoff B, Caldera FE. Osteoarthritis: pathology, diagnosis, and treatment options. The Medical clinics of North America. 2020;104:293-311.

11. Cicuttini FM, Spector TD. Osteoarthritis in the aged. Epidemiological issues and optimal management. Drugs Aging. 1995;6:409-20.

12. Guidelines for the diagnosis, investigation and management of osteoarthritis of the hip and knee. Report of a Joint Working Group of the British Society for Rheumatology and the Research Unit of the Royal College of Physicians. J R Coll Physicians Lond. 1993;27:391-6.

13. Hochberg MC, Altman RD, Brandt KD, et al. Guidelines for the medical management of osteoarthritis. Part II. Osteoarthritis of the knee. American College of Rheumatology. Arthritis Rheum. 1995;38:1541-6.

14. Chesnut $\mathrm{CH}$ 3rd, Silverman S, Andriano K, et al. A randomized trial of nasal spray salmon calcitonin in postmenopausal women with established osteoporosis: the prevent recurrence of osteoporotic fractures study. PROOF Study Group. Am J Med. 2000;109:267-76.

15. Karsdal MA, Henriksen K, Arnold M, Christiansen C. Calcitonin: a drug of the past or for the future? Physiologic inhibition of bone resorption while sustaining osteoclast numbers improves bone quality. BioDrugs. 2008;22: $137-44$.

16. Kyrkos MJ, Papavasiliou KA, Kenanidis E, Tsiridis E, Sayegh FE, Kapetanos GA. Calcitonin delays the progress of early-stage mechanically induced osteoarthritis. In vivo, prospective study. Osteoarthr Cartil. 2013;21:973-80.

17. Nielsen RH, Bay-Jensen AC, Byrjalsen I, Karsdal MA. Oral salmon calcitonin reduces cartilage and bone pathology in an osteoarthritis rat model with increased subchondral bone turnover. Osteoarthr Cartil. 2011;19:466-73.

18. El Hajjaji H, Williams JM, Devogelaer JP, Lenz ME, Thonar EJ, Manicourt DH. Treatment with calcitonin prevents the net loss of collagen, hyaluronan and proteoglycan aggregates from cartilage in the early stages of canine experimental osteoarthritis. Osteoarthr Cartil. 2004:12:904-11.

19. Bagger $Y Z$, Tanko LB, Alexandersen $P$, et al. Oral salmon calcitonin induced suppression of urinary collagen type II degradation in postmenopausal women: a new potential treatment of osteoarthritis. Bone. 2005;37:425-30.
20. Manicourt DH, Azria M, Mindeholm L, Thonar EJ, Devogelaer JP. Oral salmon calcitonin reduces Lequesne's algofunctional index scores and decreases urinary and serum levels of biomarkers of joint metabolism in knee osteoarthritis. Arthritis Rheum. 2006:54:3205-11.

21. Karsdal MA, Byrjalsen I, Henriksen $\mathrm{K}$, et al. The effect of oral salmon calcitonin delivered with 5-CNAC on bone and cartilage degradation in osteoarthritic patients: a 14-day randomized study. Osteoarthr Cartil. 2010;18:150-9.

22. Kuttapitiya A, Assi L, Laing K, et al. Microarray analysis of bone marrow lesions in osteoarthritis demonstrates upregulation of genes implicated in osteochondral turnover, neurogenesis and inflammation. Ann Rheum Dis. 2017:76:1764-73.

23. Micklewright R, Lane S, Linley W, McQuade C, Thompson F, Maskrey N. Review article: NSAIDs, gastroprotection and cyclo-oxygenase-II-selective inhibitors. Aliment Pharmacol Ther. 2003;17:321-32.

24. Bensen WG, Fiechtner JJ, McMillen Jl, et al. Treatment of osteoarthritis with celecoxib, a cyclooxygenase-2 inhibitor: a randomized controlled trial. Mayo Clin Proc. 1999;74:1095-105.

25. Hunter DJ, Bierma-Zeinstra S. Osteoarthritis. Lancet (London, England). 2019; 393:1745-59.

26. Altman R, Asch E, Bloch D, et al. Development of criteria for the classification and reporting of osteoarthritis. Classification of osteoarthritis of the knee. Diagnostic and Therapeutic Criteria Committee of the American Rheumatism Association. Arthritis Rheum. 1986;29:1039-49.

27. Kellgren JH, Lawrence JS. Radiological assessment of osteo-arthrosis. Ann Rheum Dis. 1957;16:494-502.

28. Felson DT, McLaughlin S, Goggins J, et al. Bone marrow edema and its relation to progression of knee osteoarthritis. Ann Intern Med. 2003;139: 330-6.

29. Gao F, Sun W, Li Z, Guo W, Kush N, Ozaki K. Intractable bone marrow edema syndrome of the hip. Orthopedics. 2015;38:e263-70.

30. Aigner N, Meizer R, Petje G, Meizer E, Abdelkafy A, Landsiedl F. Natural course of intra-articular shifting bone marrow edema syndrome of the knee. BMC Musculoskelet Disord. 2008;9:45.

31. Peterfy CG, Guermazi A, Zaim S, et al. Whole-Organ Magnetic Resonance Imaging Score (WORMS) of the knee in osteoarthritis. Osteoarthr Cartil. 2004;12:177-90.

32. Scott PJ, Huskisson EC. Measurement of functional capacity with visual analogue scales. Rheumatol Rehabil. 1977:16:257-9.

33. Dieppe P, Cushnaghan J, Young P, Kirwan J. Prediction of the progression of joint space narrowing in osteoarthritis of the knee by bone scintigraphy. Ann Rheum Dis. 1993;52:557-63.

34. Felson DT, Niu J, Guermazi A, et al. Correlation of the development of knee pain with enlarging bone marrow lesions on magnetic resonance imaging. Arthritis Rheum. 2007;56:2986-92

35. Laslett LL, Doré DA, Quinn SJ, et al. Zoledronic acid reduces knee pain and bone marrow lesions over 1 year: a randomised controlled trial. Ann Rheum Dis. 2012:71:1322-8

36. Roemer FW, Guermazi A, Javaid MK, et al. Change in MRI-detected subchondral bone marrow lesions is associated with cartilage loss: the MOST Study. A longitudinal multicentre study of knee osteoarthritis. Ann Rheum Dis. 2009:68:1461-5.

37. Zanetti M, Bruder E, Romero J, Hodler J. Bone marrow edema pattern in osteoarthritic knees: correlation between MR imaging and histologic findings. Radiology. 2000;215:835-40,

38. Rezende RM, Paiva-Lima P, Dos Reis WGP, Camêlo VM, Bakhle YS, de Francischi JN. Celecoxib induces tolerance in a model of peripheral inflammatory pain in rats. Neuropharmacology. 2010;59:551-7.

39. Wildi LM, Raynauld J-P, Martel-Pelletier J, et al. Chondroitin sulphate reduces both cartilage volume loss and bone marrow lesions in knee osteoarthritis patients starting as early as 6 months after initiation of therapy: a randomised, double-blind, placebo-controlled pilot study using MRI. Ann Rheum Dis. 2011;70:982-9.

40. Raynauld J-P, Martel-Pelletier J, Beaulieu A, et al. An open-label pilot study evaluating by magnetic resonance imaging the potential for a disease-modifying effect of celecoxib compared to a modelized historical control cohort in the treatment of knee osteoarthritis. Semin Arthritis Rheum. 2010;40:185-92.

41. Munoz-Torres M, Alonso G, Raya MP. Calcitonin therapy in osteoporosis. Treat Endocrinol. 2004;3:117-32.

42. Papaioannou NA, Triantafillopoulos IK, Khaldi L, Krallis N, Galanos A, Lyritis GP. Effect of calcitonin in early and late stages of experimentally induced osteoarthritis. A histomorphometric study. Osteoarthr Cartil. 2007;15:386-95. 
43. Behets C, Williams JM, Chappard D, Devogelaer JP, Manicourt DH. Effects of calcitonin on subchondral trabecular bone changes and on osteoarthritic cartilage lesions after acute anterior cruciate ligament deficiency. J Bone Miner Res. 2004:19:1821-6.

44. Haavardsholm EA, Boyesen P, Ostergaard M, Schildvold A, Kvien TK. Magnetic resonance imaging findings in 84 patients with early rheumatoid arthritis: bone marrow oedema predicts erosive progression. Ann Rheum Dis. 2008;67:794-800.

45. Arayssi TK, Tawbi HA, Usta IM, Hourani MH. Calcitonin in the treatment of transient osteoporosis of the hip. Semin Arthritis Rheum. 2003;32:388-97.

46. Varenna M, Sinigaglia L, Binelli L, Beltrametti P, Gallazzi M. Transient osteoporosis of the hip: a densitometric study. Clin Rheumatol. 1996;15:16973.

47. Zhou J, Li T, Li L, Xue Y. Clinical efficacy of calcitonin compared to diclofenac sodium in chronic nonspecific low back pain with type I Modic changes: a retrospective study. J Pain Res. 2018;11:1335-42.

48. Maldonado $\mathrm{M}, \mathrm{Nam} \mathrm{J}$. The role of changes in extracellular matrix of cartilage in the presence of inflammation on the pathology of osteoarthritis. Biomed Res Int. 2013;2013:284873.

49. Lin EA, Liu CJ. The role of ADAMTSs in arthritis. Protein Cell. 2010;1:33-47.

50. Bjordal JM, Klovning A, Ljunggren AE, Slørdal L. Short-term efficacy of pharmacotherapeutic interventions in osteoarthritic knee pain: a metaanalysis of randomised placebo-controlled trials. European journal of pain (London, England). 2007;11(2):125-38.

51. Reginster JY, Reiter-Niesert S, Bruyère $\mathrm{O}$, et al. Recommendations for an update of the 2010 European regulatory guideline on clinical investigation of medicinal products used in the treatment of osteoarthritis and reflections about related clinically relevant outcomes: expert consensus statement. Osteoarthr Cartil. 2015;23(12):2086-93.

52. Alliston T, Hernandez CJ, Findlay DM, Felson DT, Kennedy OD. Bone marrow lesions in osteoarthritis: what lies beneath. Journal of orthopaedic research : official publication of the Orthopaedic Research Society. 2018;36:1818-25.

53. McCarthy EF. The pathology of transient regional osteoporosis. lowa Orthop J. 1998; 18:35-42.

54. Berger $\mathrm{CE}$, Kroner $\mathrm{AH}$, Minai-Pour MB, Ogris E, Engel A. Biochemical markers of bone metabolism in bone marrow edema syndrome of the hip. Bone. 2003:33:346-51.

55. Eriksen EF, Ringe JD. Bone marrow lesions: a universal bone response to injury? Rheumatol Int. 2012;32:575-84.

\section{Publisher's Note}

Springer Nature remains neutral with regard to jurisdictional claims in published maps and institutional affiliations.

Ready to submit your research? Choose BMC and benefit from:

- fast, convenient online submission

- thorough peer review by experienced researchers in your field

- rapid publication on acceptance

- support for research data, including large and complex data types

- gold Open Access which fosters wider collaboration and increased citations

- maximum visibility for your research: over $100 \mathrm{M}$ website views per year

At $\mathrm{BMC}$, research is always in progress.

Learn more biomedcentral.com/submissions 